\title{
TAKING INVESTMENT DECISIONS ON THE FUTURES CONTRACTS MARKET WITH THE APPLICATION OF BAT HARMONIC PATTERN - THE INCREASED EFFICIENCY OF INVESTMENT
}

Krzysztof Bednarz, Ph.D.

\begin{abstract}
The Bat harmonic pattern presented in the article shows that transactions made thanks to it on the contract market are characterized by an above-average rate of return (206.43\% within 27 days) while accepting the initial risk (R). The use of the potential reversal zone (PRZ) calculated thanks to the Fibonacci retracements (internal and external retracements as well as pricing projections) makes profits that arise in such a short time to be considered impressive. This article presents also one of the simple methods of profits protection which involves exceeding the local maximum (for a short position) or the local minimum (for a long position), modified by the degree of the accepted risk $(R)$.

It is worth noting that the POO can be calculated for several hours (days, weeks, months - depending on the time interval) before the actual transaction is concluded. In this, among other things, the harmonic trading with XABCD pattern differs from many other investment methods. This is a decision making based on the data available up to the last bar in the chart of what is likely to happen after this last bar. You could even say that POO is buying fear when prices are falling heavily and selling greed when prices are rising rapidly.
\end{abstract}

Keywords: Bat, retracements, internal price retracements, external price retracements, the potential reversal zone, harmonic pattern, Fibonacci, Fibonacci's numbers.

JEL classification: C53, C65, G11, G17, G24. 


\section{It would be difficult to expect that someone without proper skill and talent could be a good violin player. The same is with analysing chart ${ }^{1}$.}

J.D. Schwager

\section{Introduction}

Investment on the capital market always involves taking decisions and requires certain skill and talent, as J.D. Schwager claims. Such activity can be approached as any other business where decisions are not always optimal and where there is a considerable risk in cooperation with potential contractors. Nevertheless, application of certain strategies enables "survival" both on the competitive market and on the capital market (especially where there is leverage, as for example in the futures contracts trade).

While planning a transaction, an investor has the following data:

- information (macroeconomic information, data from financial reports, other),

- a record of previous quotations in the form of a graph.

However, it should be remembered that no method of fundamental analysis or technical analysis is $100 \%$ sure. This is due to the fact that inevitable elements of investment are also emotions which usually influence investment decisions. While with fundamental analysis it is relatively easy to identify which financial instrument should be bought (or sold), investment with technical analysis is always done on the right (blank) side of the chart, after the last known column. Thus, it is necessary to seek occasions where the intended scenario of events is highly probable.

Among many methods of taking investment decisions, there is a growing focus on Fibonacci price retracements ${ }^{2}$ which are available in almost all software for technical analysis. Moreover, the practice of harmonic investment, which uses Fibonacci ratios in the form of specific price structures, becomes increasingly widespread. Therefore, the goal of the article is:

- $\quad$ to present the Bat harmonic pattern, described with particular Fibonacci ratios, and

- $\quad$ to present efficiency of investment with the application of this pattern in real investments on the contract market. It will be used to specify the moment of the transaction initiating, owing to identification of the potential reversal zone ${ }^{3}$ (PRZ) many hours (days) earlier. Furthermore, a certain technique of leaving the market (closing positions) will be presented, taking into account the initial risk $(R)$ accepted by the investor.

Practical application of harmonic patterns in investment and the use of stop-loss order confirms that, owing to this strategy, the started transactions are characterized by relatively low risk (accepted by the investor), and at the same time by increased efficiency. 
The article contains a number of charts from AmiBroker: a professional stock-market software used by the author in real investments. The observation method is used to present the material (the analysis of stock-market quotations using intraday data at 1-hour intervals and end-of-day data), as well as the method of comparison with models (the comparison with the postulated features).

\section{Fibonacci sequence and resulting ratios}

In mathematics, a sequence is a series of consecutive numbers, linked by a specific relation. The presented sequence is as follows: $1,1,2,3,5,8,13,21,34,55,89,144,233(\ldots)^{4}$. It is structured in such a way that each subsequent number is a sum of two previous numbers, that is: $5=3+2 ; 233=144+89$, etc. The discussed sequence exhibits a number of qualities. The most important are the proportions, where the relation of a selected number to the following one equals ca 0.618 , while the relation of a selected number to the previous one is approximately 1.618. Between the numbers separated by two positions, these relations are respectively: 0.382 and 2.618. This feature is especially precise for a quotient of larger numbers in the sequence, e.g. $34 / 55=0.618$ or $55 / 34=1.618^{5}$. The quantity 0.618 is called $p h i(\varphi)$.

The presented ratios, and specifically the proportions related to them, are regarded as the classic model of beauty. With the development of civilization, especially arts, the notion of "golden ratio" (or: "golden section", "golden cut") became recognized. According to the encyclopaedia ${ }^{6}$, it is the division of a quantity $a$ into such two parts, i.e. $x$ and $a-x$, that the ratio of the whole sum to the larger part $x$ is equal to the ratio of the larger part to the smaller one $a-x$, that is:

$$
\frac{a}{x}=\frac{x}{a-x}
$$

Consequently, it follows that:

- the larger part equals: $x=\frac{\sqrt{5}-1}{2} \cdot a$,

- the smaller part equals: $a-x=\frac{3-\sqrt{5}}{2} \cdot a$.

These ratios are presented graphically in Figure 1. 


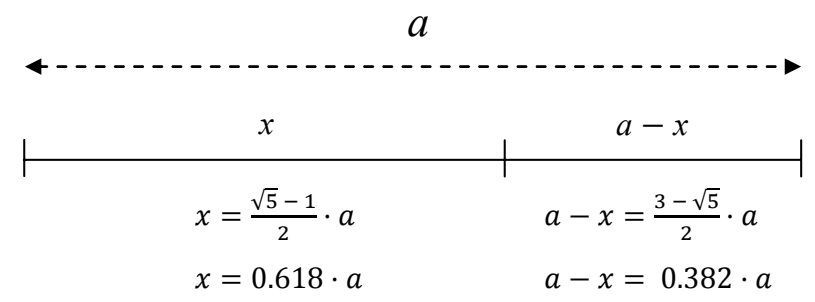

Fig. 1. Golden ratio (golden section, golden cut)

Source: prepared by the author and: Bednarz (2011), p. 205.

The features of the presented sequence are also connected with other quantities, referred to as "Fibonacci ratios". They are presented in Table 1.

Table 1. Fibonacci ratios obtained from raising the numbers: $0.382 ; 0.618$ and 1.618 to the appropriate exponent

\begin{tabular}{|c|c|c|c|c|c|c|c|c|c|}
\hline \multirow[b]{2}{*}{ Number } & \multicolumn{9}{|c|}{ Exponent } \\
\hline & 4 & 3.5 & 3 & 2.5 & 2 & 1 & 0.5 & 0.25 & 0 \\
\hline 0.382 & \multirow{4}{*}{$\begin{array}{l}0.146 \\
6.854\end{array}$} & \multirow{4}{*}{0.186} & \multirow{4}{*}{$\begin{array}{l}0.236 \\
4.236\end{array}$} & \multirow{3}{*}{0.3} & 0.146 & 0.382 & 0.618 & 0.786 & 1 \\
\hline 0.618 & & & & & 0.382 & 0.618 & 0.786 & 0.886 & 1 \\
\hline 1.618 & & & & & 2.618 & 1.618 & 1.272 & 1.128 & 1 \\
\hline & & & & \multicolumn{3}{|c|}{ Fibonacci ratios } & & & \\
\hline
\end{tabular}

Source: own calculation.

\section{Bat pattern - presentation}

In his "Technical Analysis of Financial Markets", John J.Murphy explains the notion of patterns. According to him, these are "certain shapes or models which appear on charts with prices of shares or goods. Patterns can be divided into separate categories and used to predict future movement of prices"7. Such models (shapes) include also harmonic structures of prices, where the relations between particular waves are described with the above-mentioned Fibonacci ratios. One of them is Bat pattern shown in Figure 2. Harmonic patters are also referred to as $\mathrm{XABCD}{ }^{8}$ structures (shapes). 
S. Carney describes this harmonic structure by means of Fibonacci ratios which "retrace" (correct) the earlier wave:

1) $\mathrm{AB}$ wave constitutes from 0.382 to 0.5 of the range of XA wave (retraces between $38.2 \%$ and $50 \%$ of XA wave: this is an internal retracement of XA wave), that is: $\mathrm{AB}=$ 0.382 XA (maximum: $\mathrm{AB}=0.5 \mathrm{XA}$ );

2) $\mathrm{BC}$ wave constitutes from 0.382 to 0.886 of the range of $\mathrm{AB}$ wave (retraces between $38.2 \%$ and $88.6 \%$ of $\mathrm{AB}$ wave, that is: $\mathrm{BC}=0.382 \mathrm{AB}$ (maximum: $\mathrm{BC}=0.886 \mathrm{AB}$ );

3) $\mathrm{CD}$ wave constitutes an external retracement ${ }^{9}$ of $\mathrm{BC}$ wave; it retraces between $161.8 \%$ and $261.8 \%$ of $\mathrm{BC}$ wave, that is: $\mathrm{CD}=1.618 \mathrm{BC}$ (maximum: $\mathrm{CD}=2.618 \mathrm{BC}$ );

4) Sequence of waves: $\mathrm{ABCD}$ constitutes 0.886 of the range of $\mathrm{XA}$ wave (retraces $88.6 \%$ of XA wave), that is: $\mathrm{AD}=0.886 \mathrm{XA}$; this is an internal retracement of $\mathrm{XA}$ wave,

5) Point $\mathrm{D}$ is a projection (a calculated, probable future quantity, ending the pattern); this is a convenient position to enter the market in the direction consistent with XA wave.

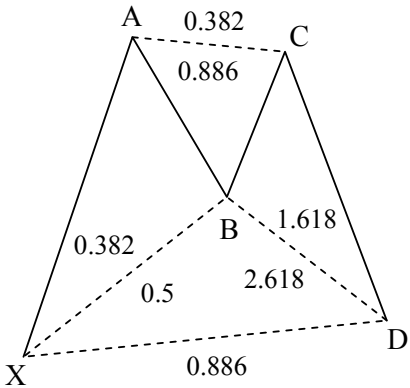

1) on the bull market

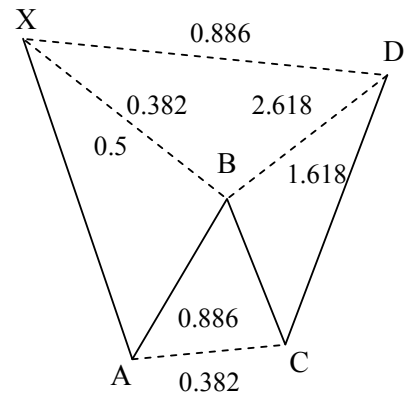

2) on the bear market

Fig. 2. Bat harmonic pattern

Source: Carney (2010), pp. 72, 83.

While discussing harmonic structures it should be remembered that in each XABCD pattern, out of 5 points (vertices) only 4 are known (that is: $\mathrm{X}, \mathrm{A}, \mathrm{B}, \mathrm{C}$ ). Point $\mathrm{D}$ is specified much earlier (many months, weeks, days, hours, minutes - depending on the time interval used in graphs) before it actually appears in stock market quotations. It is possible only after the vertex $\mathrm{C}$ is formed. 
The proximity of the internal retracement of $88.6 \%$ XA wave and D point projection (measured as external retracement of $\mathrm{BC}$ wave ranging from $161.8 \%$ to $261.8 \%$ ) indicates harmony and unanimity. In this area, the potential reversal zone ${ }^{10}$ (PRZ) is outlined. Based on experience, in this zone it is highly probable that the tendency specified by XA wave will be continued. Therefore, outlining of PRZ is very important when using harmonic patterns to make investment decisions. "Owing to these zones, entering the market is less risky and enables generation of profit from investments with high rate of return"11.

\section{Application of Bat harmonic pattern in real transactions on the futures market - efficiency of investments}

\subsection{Methodology of transaction - entry level, stop-loss order, exit level}

In order to present investment efficiency (the second research goal in the introduction) by means of the Bat harmonic pattern, a futures contract for WIG20 index with completion date in March (FW20H12) will be used. The "life" of the instrument is from 21.03.2011 to 16.03.2012.

In the presented way of opening the positions, entry on the market is planned in the middle of PRZ using intra-day data (in one case the end-of-day information is used). This will be the first order initiating the transaction. The second is SL an order which should definitely be placed just after entering the market. It is worth noticing that various methods of determining SL value are applied in the investment practice. The long-term moving average is frequently used. Axial points (upper and lower) are an interesting idea as well ${ }^{12}$. In the presented investment method another frequent manner of determining SL is applied. However, it is modified here by the degree of the accepted risk $(R)$. Thus, SL is presented as follows:

- $\mathrm{SL}_{(\mathrm{WE})}$ - this is the first SL connected with the entry on the market, which is placed directly after opening of the position; its value is equal to the accepted risk which, in this case, is 14 points (that is 140 PLN, which accounts for approximately $10 \%$ of the margin value; thus $\mathrm{SL}_{(\mathrm{WE})}=R$;

- $\mathrm{SL}_{(2 \mathrm{a})}, \mathrm{SL}_{(2 \mathrm{~b})}, \mathrm{SL}_{(2 \mathrm{c})}$ - these are the next values of $\mathrm{SL}$ which are modified in relation to the previous local maximum (for a short futures position) and local minimum (for a long futures position). To these values, $0.5 R$ will be respectively added/subtracted; modification of local extremes seems necessary, because SL orders of other investors are usually placed around them. 
The presented transactions are shown in charts at 1-hour and 1-day intervals. However, it is impossible to present all the existing patterns. Therefore, out of necessity, only these patterns will be shown which are the most corresponding to Bat structure. It is worth adding that in the quotations of the discussed financial instrument there are a number of other harmonic structures, such as: Gartley 222, Butterfly, Crab, $\mathrm{AB}=\mathrm{CD}$, which, however, have not been presented.

\subsection{Bat patterns noticed in quotations of FW20H12 futures contract}

The first visible Bat pattern in the hourly graph is presented in Figure 3a which depicts particular internal and external retracements and the projection of the target point, that is the $\mathrm{D}$ vertex as the place of opening a long futures position.

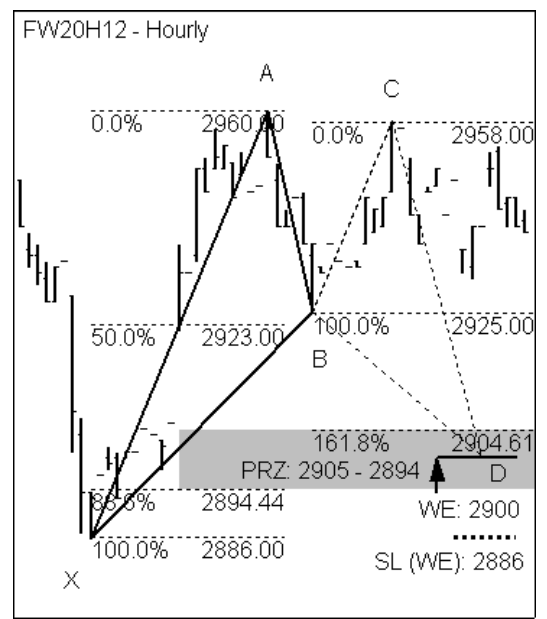

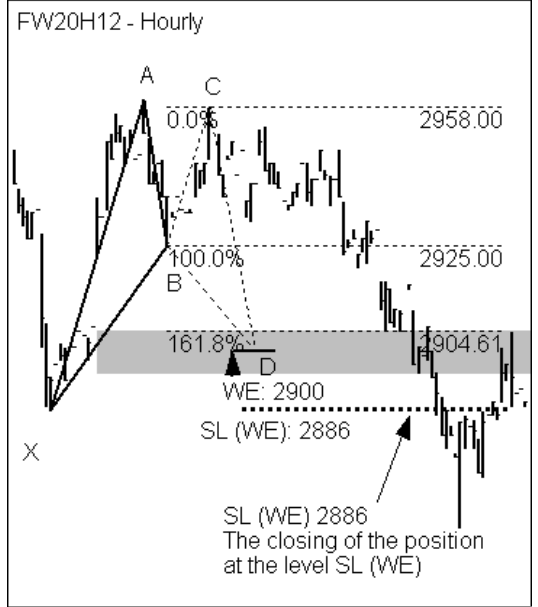

$\mathrm{b}$

$\begin{array}{lllll}\mathrm{WE}=2900 & \mathrm{SL}_{(\mathrm{WE})}=2886 & \mathrm{PRZ}(2905-2894) & \\ \mathrm{X}=2886 & \mathrm{~A}=2960 & \mathrm{~B}=2925 & \mathrm{C}=2958 & \mathrm{D}=? \\ \mathrm{XA}=74 & \mathrm{AB}=35 & \mathrm{BC}=33 & & \end{array}$

Fig. 3. FW20H12 (hourly, long futures position) - pattern 1

Source: prepared by the author with AmiBroker software.

Description 1 of a potential Bat pattern, Figure 3a

1) $\mathrm{AB}$ wave stopped 2 points above $50 \%$ retracement of XA wave at the level of 2925; full $50 \%$ retracement equals $2923[2923=2960-(74 \cdot 50 \%)] ;$

2 ) the following $\mathrm{BC}$ wave rose 2 points above $88.6 \%$ retracement of the previous $\mathrm{AB}$ wave and stopped at the level of 2958; 88.6\% retracement for $\mathrm{AB}$ wave equals precisely $2956.01[2956.01=2925+(35 \cdot 88.6 \%)]$; 
3) the shorter external retracement of BC wave is at the level of 2904.61 [2904.61= $2958-(33 \cdot 161.8 \%)]$;

4) the close proximity of $88.6 \%$ internal retracement of XA wave which equals 2894.44 $[2894.44=2960-(74 \cdot 88.6 \%)]$ and the external retracement of BC wave described with 161.8\% quotient (as above) enable identification of PRZ (the potential reversal zone) between 2905 and 2894 (approximated values); in the graph PRZ is marked in grey colour;

5) in case that the change in the rate reaches PRZ, the long futures position will be opened in the middle of it, which in the presented case equals $\mathrm{WE}_{(\mathrm{LONG})}=2900[2900=[(2905-$ $2894) / 2]+2894] ; \mathrm{SL}_{(\mathrm{WE})}$ for such an opened position is $2886[2886=2900-R]$.

Finally, after five hours of quotation, the position is closed at the $\mathrm{SL}_{(\mathrm{WE})}$ level. The loss amounts to 140 PLN and is equal to the accepted initial risk $R$.

The second Bat pattern in the hourly graph is presented in Figure 4a. In this case, a convenient moment to initiate a short futures position will be sought. It is worth paying attention to the gap (indicated by the arrow). In the transaction practice, Fibonacci retracements are very often identified in relation to gaps.

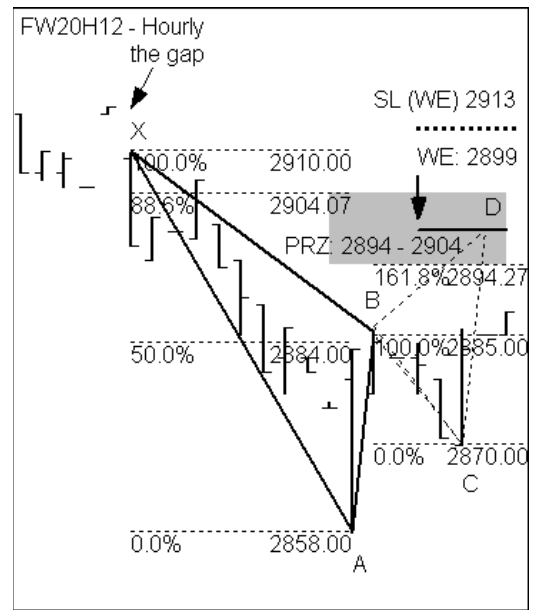

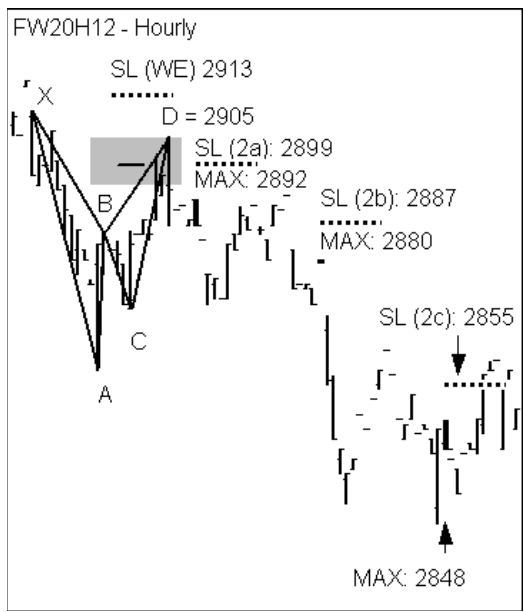

b
$\mathrm{WE}=2899$
$\mathrm{SL}_{(\mathrm{WE})}=2913$
PRZ (2894-2904)
$\mathrm{X}=2910$
$\mathrm{A}=2858$
$\mathrm{B}=2885$
$\mathrm{C}=2870$
$\mathrm{D}=$ ?
$\mathrm{XA}=52$
$\mathrm{AB}=27$
$\mathrm{BC}=15$

Fig. 4. FW20H12 (hourly, short futures position) - pattern 2

Source: prepared by the author with AmiBroker software. 
Description 2 of a potential Bat pattern, Figure $4 \mathrm{a}$

1) $\mathrm{AB}$ wave stopped 1 point above $50 \%$ retracement of XA wave at the level of 2885 ; full $50 \%$ retracement equals $2884[2884=2910-(52 \cdot 50 \%)] ;$

2 ) the following $\mathrm{BC}$ wave stopped almost exactly in the middle of the previous $\mathrm{AB}$ wave at the level of $2870 ; 50 \%$ retracement for $\mathrm{AB}$ wave equals precisely 2871.5 [2871.5 = $2885-(27 \cdot 50 \%)]$;

3) shorter external retracement of $\mathrm{BC}$ wave equals $2894.27[2894.27=2870+$ $(15 \cdot 161.8 \%)]$

4) PRZ covers the range of (2894 - 2904) which is marked in grey colour in the graph; number 2904 is the internal retracement of XA wave with the quotient at $88.6 \%$;

5 ) in case that change in the rate reaches PRZ, the short futures position will be opened in the middle of it, which in the presented case equals: $\mathrm{WE}_{(\mathrm{SHORT})}=2899[2899=[(2904$ - 2894)/2] + 2894]; $\mathrm{SL}_{(\mathrm{WE})}$ for such an opened position is $2913[2913=2899+R]$.

Finally, the opening of a short futures position occurred at the calculated level of 2899 , after which change in the rate rose precisely to the level of $88.6 \%$ internal retracement of XA wave, that is only by 6 points (60 PLN) more than the initiated transaction. Closing of the position occurred as a result of moving stop-loss order at the level $\mathrm{SL}_{(2 \mathrm{c})}=2855$. Profit from the position was 44 points, that is 440 PLN [ $44=2899-2855]$, which accounts for $31.43 \%$ within 6 days.

The third Bat pattern in the hourly graph is presented in Figure 5a. It can be described as follows:

1) $\mathrm{AB}$ wave stopped 0.5 point below $50 \%$ retracement of $\mathrm{XA}$ wave at the level 2873; full $50 \%$ retracement equals precisely $2873.5[2873.5=2854+(39 \cdot 50 \%)] ;$

2) the following $\mathrm{BC}$ wave corrected the previous $\mathrm{AB}$ by $61.8 \%$ and stopped at the level of $2861[2861.2=2873-(19 \cdot 61.8 \%)] ;$

3) shorter external retracement of $\mathrm{BC}$ wave equals $2880.42[2880.42=2861+$ $(12 \cdot 161.8 \%)]$

4) PRZ covers the range of $(2880$ - 2889) which is marked in grey colour in the graph;

5 ) in case that change in rate reaches PRZ, the short futures position will be opened in the middle of it, which in the presented case equals: $\mathrm{WE}_{(\mathrm{SHORT})}=2885[2884.5=[(2889-$ $2880) / 2]+2880] ; \mathrm{SL}_{(\mathrm{WE})}$ for such an opened position is $2899[2899=2885+R]$. 


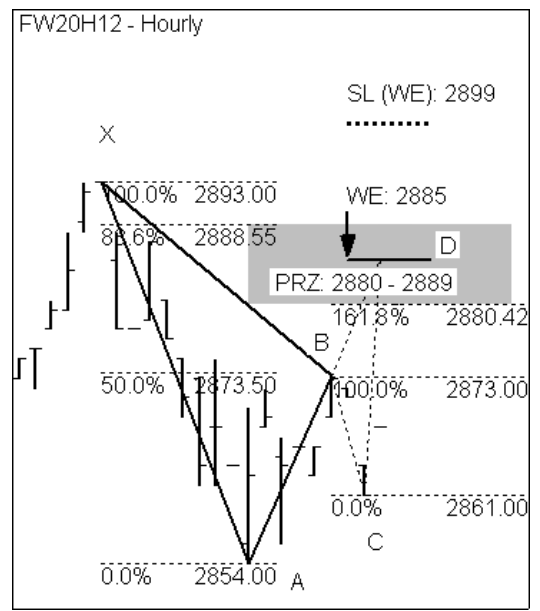

a

$\mathrm{WE}=2885$

$\mathrm{X}=2893$

$\mathrm{XA}=39$

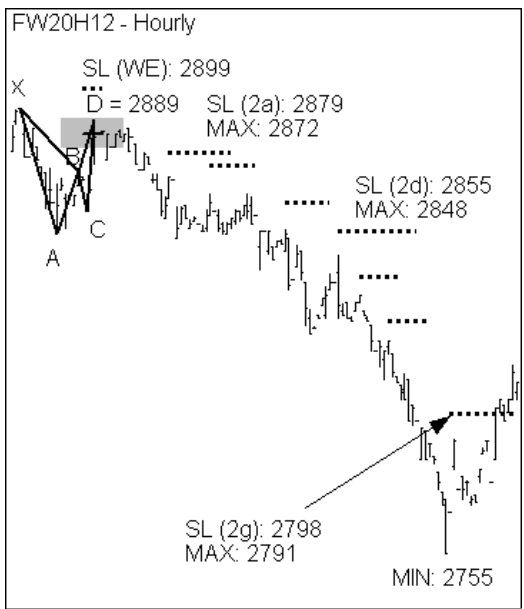

b

Fig. 5. FW20H12 (hourly, short futures position) - pattern 3

Source: prepared by the author with AmiBroker software.

Opening of the transaction occurred in accordance with the calculated value (2885), after which the change in the rate rose by 4 points to the level of 2889 , that is to $88.6 \%$ of the internal retracement of the XA wave $[2888.5=2854+(39 \cdot 88.6 \%)]$. Closing of the position occurred as a result of moving stop-loss order at the level $\mathrm{SL}_{(2 \mathrm{~g})}=2798[2798=2791+7]$. The dotted line in Figure $5 \mathrm{~b}$ presents the levels of local maxima, increased by the half of the accepted risk $R$. Finally, the profit from the position was 87 points, that is 870 PLN [ $87=2885-2798$ ], which accounts for $62.14 \%$ within 9 days. It is worth noticing that in minimum quotations (2755) the rate of return from such an opened investment was $92.86 \%$ [2885 - $2755=130$ points $=$ 1300 PLN; $1300: 1400=92.86 \%$ ].

The fourth Bat pattern in the hourly graph is presented in Figure 6a. As before, a convenient moment to initiate a transaction - short sale - will be sought. 


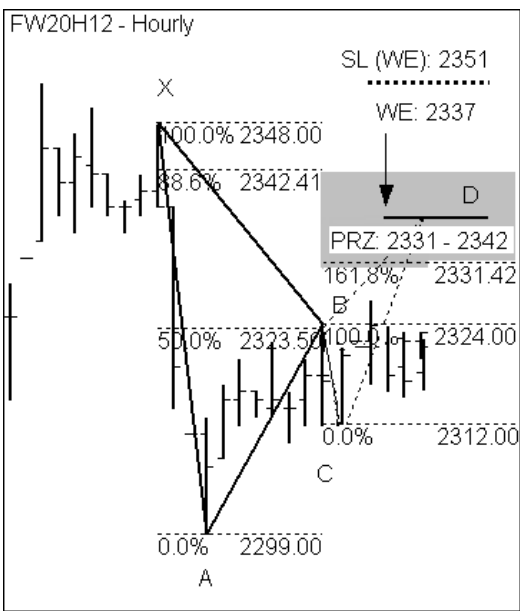

a

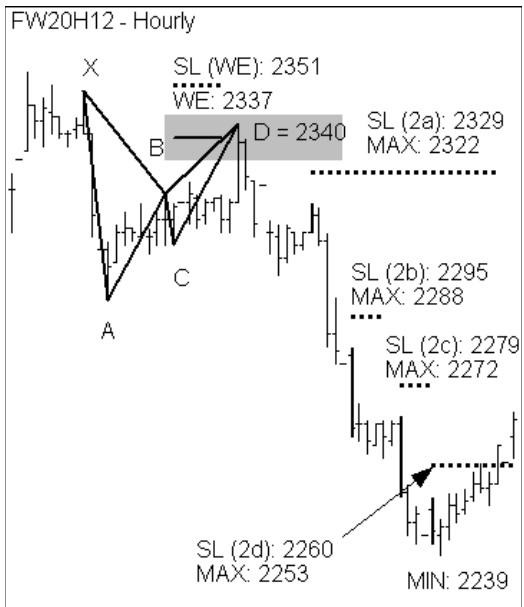

b
$\mathrm{WE}=2337$
$\mathrm{X}=2348$
$\mathrm{SL}_{(\mathrm{WE})}=2351$
PRZ (2331 - 2342)
$\mathrm{XA}=49$
$\mathrm{A}=2299$
$\mathrm{AB}=25$
$\mathrm{B}=2324$
$\mathrm{C}=2312$
$\mathrm{D}=$ ?

Fig. 6. FW20H12 (hourly, short futures position) - pattern 4

Source: prepared by the author with AmiBroker software.

Description 4 of a potential Bat pattern, Figure $6 \mathrm{a}$

1) the $\mathrm{AB}$ wave stopped in the middle of $50 \%$ retracement of the XA wave at the level of 2324; full 50\% retracement equals precisely $2323.5[2323.5=2299+(49 \cdot 50 \%)]$;

2) the following $\mathrm{BC}$ wave corrected the previous $\mathrm{AB}$ wave by $50 \%$ and stopped at the level of 2312 [2311.5 = 2324 - $(25 \cdot 50 \%)]$;

$3)$ shorter external retracement of the $\mathrm{BC}$ wave equals $2331.42[2331.42=2312+$ $(12 \cdot 161.8 \%)]$

4) PRZ covers the range of (2331 - 2342), which is marked in grey colour in the graph;

5 ) in case of the change in the rate reaching PRZ, the short futures position will be opened in the middle of it, which in the presented case equals: $\mathrm{WE}_{(\mathrm{SHORT})}=2337[2337=[(2342-$ $2331) / 2]+2331] ; \mathrm{SL}_{(\mathrm{WE})}$ for such an opened position is $2351[2351=2337+R]$.

Concluding of the transaction occurred in accordance with the calculated value (2337), after which the change of the rate rose by 3 points to the level of 2340 , that is almost to $88.6 \%$ of the internal retracement of the XA wave $[2342.41=2299+(49 \cdot 88.6 \%)]$. Closing of the position occurred as a result of moving stop-loss order at the level $\mathrm{SL}_{(2 \mathrm{~d})}=2260[2260=2253+7]$. Finally, the profit from the position was 77 points, that is 770 PLN [77=2337-2260], which accounts 
for $55 \%$ within 3 days. In the minimum of quotations (2239) the rate of return from such an opened investment was 70\% [2337 - 2239 = 98 points $=980$ PLN; $980: 1400=70 \%]$.

Harmonic structures occur also at other time intervals. In the next graph (Figure 7) the Bat pattern is shown in daily quotations. PRZ, entry level and SL are calculated on the basis of the end-of-day data.
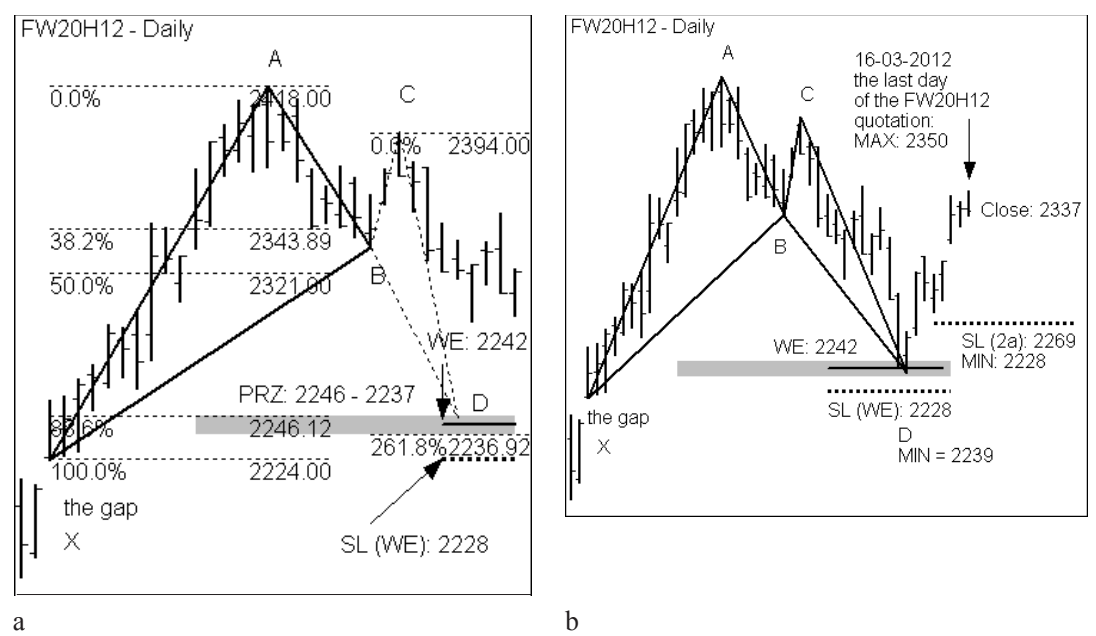

$\begin{array}{lllll}\mathrm{WE}=2242 & \mathrm{SL}_{(\mathrm{WE})}=2228 & \mathrm{PRZ}(2246-2237) & \\ \mathrm{X}=2224 & \mathrm{~A}=2418 & \mathrm{~B}=2334 & \mathrm{C}=2394 & \mathrm{D}=? \\ \mathrm{XA}=194 & \mathrm{AB}=84 & \mathrm{BC}=1260 & \end{array}$

Fig. 7. FW20H12 (daily, long position) - pattern 5

Source: prepared by the author with AmiBroker software.

Description 5 of a potential Bat pattern, Figure 7a

1) the $\mathrm{AB}$ wave corrected the previous $\mathrm{XA}$ wave by $43.3 \%$ and stopped at the level of $2334[2334=2418-(194 \cdot 43.3 \%)] ; 43.3 \%$ retracement falls within the retracements accepted for the XA wave;

2) the following $\mathrm{BC}$ wave corrected the previous $\mathrm{AB}$ wave by $71.43 \%$ and stopped at the level of $2394[2394=2334+(84 \cdot 71.43 \%)], 71.43 \%$ retracement falls within the retracements accepted for the $\mathrm{AB}$ wave;

3 ) the longer external retracement of the $\mathrm{BC}$ wave equals $2236.92[2236.92=2394-$ $(60 \cdot 261.8 \%)] ;$

4) PRZ covers the range of $(2246$ - 2237), which in the graph is marked with grey colour; 
5) if the change in the rate reaches PRZ, a long futures position will be opened in the middle of it: $\mathrm{WE}_{(\mathrm{LONG})}=2242[2242=[(2246-2237) / 2]+2237] ; \mathrm{SL}_{(\mathrm{WE})}$ for such an opened position is 2228 [ $2228=2242-R]$.

Opening of a long futures position occurred in accordance with the calculated value (2242) on 6.03.2012 and at the same time it was the lowest value of quotations on this day. On the next day (7.03.2012) the opening was at the level of 2250 (not indicated in the picture), after which, in relation to the minimum price from the previous day, the price decreased by almost $161.8 \%$ (without two points) to the level of 2239 [2237.06 $=2250-(2250-2242) \cdot 161.8 \%]$. Finally, the profit from the position was 95 points, that is 950 PLN [95 = $2337-2242]$, which accounts for $67.86 \%$ within 8 days. In the maximum of quotations (2350) the rate of return from such an opened investment was 70\% [2350 - 2242 = 108 points $=1080$ PLN; $1080: 1400=7714 \%]$. However, for the calculation of profit from the position the settlement price (2337) of a contract from this series was adopted, because the day of 16.03.2012 was the last day of quoting of the futures contract marked as FW20H12 on WIG20.

\section{Summary of investment efficiency carried out with the application of the harmonic Bat pattern}

The transactions initiated in PRZ turned out to be very profitable, as it is shown in Table 2. Thus, the second research goal has been achieved. Even if not all of the transactions resulted in profit, their total rate of return equalled $206.43 \%$ during only 27 days of their presence on the market. A stop-loss order enabled closing a loss-making position (the Bat pattern 1) at the level

Table 2. Presentation of investment efficiency of Bat harmonic patterns margin (investment value) $=1400$ PLN

initial risk accepted by the investor $R=140$ PLN (14 points, 10 per cent of the margin)

\begin{tabular}{|c|c|c|c|c|c|c|}
\hline \multirow{2}{*}{$\begin{array}{c}\text { BAT } \\
\text { pattern }\end{array}$} & \multicolumn{3}{|c|}{ Position } & \multirow{2}{*}{$\begin{array}{c}\text { Profit/loss } \\
\text { (PLN) }\end{array}$} & $\begin{array}{c}\text { Rate of return } \\
(\%)\end{array}$ & $\begin{array}{c}\text { Time } \\
\text { of investment }\end{array}$ \\
\cline { 2 - 7 } & position & open & close & D & F & G \\
\hline A & B & C & D & -140 & -10.00 & 5 hrs \\
\hline 1 & long & 2900 & 2886 & 440 & 31.43 & 6 days \\
\hline 2 & short & 2899 & 2855 & 870 & 62.14 & 9 days \\
\hline 3 & short & 2885 & 2798 & 770 & 55.00 & 3 days \\
\hline 4 & short & 2337 & 2260 & 950 & 67.86 & 8 days \\
\hline 5 & long & 2242 & 2337 & 2890 & 206.43 & $\approx 27$ days \\
\hline \multicolumn{7}{|c|}{ Total } \\
\hline
\end{tabular}

\begin{tabular}{|c|}
\hline $\begin{array}{c}\text { Profit } \\
\text { against } R\end{array}$ \\
\hline $\mathrm{H}$ \\
\hline$-1,00$ \\
\hline 3,14 \\
\hline 6,21 \\
\hline 5,50 \\
\hline 6,79 \\
\hline 20.64 \\
\hline
\end{tabular}

Source: prepared by the author. 
of accepted risk at 140 PLN (i.e. 14 points). Moreover, the column H shows how much money (in PLN) was generated for each risked 1 PLN $(R=140$ PLN) in particular investments (opened positions).

The results of Table 2 prove that investments made with the application of the harmonic Bat pattern are very profitable (e.g. $67.86 \%$ within 8 days: the fifth Bat pattern).

\section{Notes}

1 Schwager (2002), p. 148.

2 Boroden (2008), p. 9.

3 Carney (2010), p. 39.

4 Carney (2010), p. 11; Frost, Prechter (2005), p. 105; Boroden (2008), p. 1.

5 Bednarz (2011), p. 206.

6 Encyklopedia powszechna (1997), p. 1035.

7 Murphy (2008), p. 88.

8 Carney (2010), pp. 72-96 (Bat pattern), pp. 99-120 (Gartley 222 pattern), pp. 123-148 (Crab pattern), pp. 150-169 (Butterfly pattern).

9 Boroden (2008), pp. 29-30.

10 Carney (2010), p. 39.

11 Bednarz (2011), p. 211.

${ }^{12}$ Lebeau, Lucas (1998), pp. 226-227; Axial points on the futures contracts market in Poland, in: Bednarz (2011), pp. 213-214.

\section{References}

Bednarz, K. (2011). Formacja harmoniczna Gartley 222 jako sposób na zmniejszenie ryzyka i zwiększenie efektywności inwestycji na rynku kapitałowym. In: Rynki finansowe. Nowe wyzwania i możliwości. Prace Naukowe Wyższej Szkoły Bankowej w Gdańsku. GdańskWarszawa: WSB-CeDeWu.

Boroden, C. (2008). Fibonacci Trading. How to Master the Time and Price Advantage. New York: McGraw-Hill Inc.

Carney, S.M. (2010). Harmonic Trading. Profiting from the Natural Order of the Financial Markets (Vol. 1). New Jersey: Pearson Education Inc.

Encyklopedia powszechna. (1997) Vol. 6. Warszawa: Wydawnictwo Naukowe PWN.

Frost, A.J. \& Prechter, R.R. (2005). Elliott Wave Principle. Key to Market Behavior. Gainesville Georgia: New Classics Library Inc. 
Lebeau, Ch. \& Lucas, D.W. (1998). Komputerowa analiza rynków terminowych. Warszawa: WIG-Press.

Murphy, J.J. (2008). Analiza techniczna rynków finansowych. Warszawa: WIG-Press.

Schwager, J.D. (2002). Analiza techniczna rynków terminowych. Warszawa: WIG-Press. 